\title{
Disintegrin-Like Peptides Derived from Naturally-Occurring Proteins: A Proposed Adjunct Treatment for Cancer Therapy: A Commentary
}

\author{
Gerald J Mizejewski* \\ Division of Translational Medicine, Wadsworth Center, New York State Department of Health, Albany, NY, USA
}

${ }^{*}$ Corresponding author: Gerald J Mizejewski, Division of Translational Medicine, Wadsworth Center, New York State Department of Health, PO Box 509, Empire State Plaza, Albany, NY, 12201-0509, USA, Tel: 518 486-5900; E-mail: gerald.mizejewski@health.ny.gov

Received: 23 Mar, 2020 | Accepted: 02 Sep, 2020 | Published: 11 Sep, 2020

Citation: Mizejewski GJ (2020) Disintegrin-Like Peptides Derived from Naturally-Occurring Proteins: A Proposed Adjunct Treatment for Cancer Therapy: A Commentary. Int J Cancer Res Mol Mech 5(2): dx.doi.org/10.16966/2381-3318.147

Copyright: ( 2020 Mizejewski GJ. This is an open-access article distributed under the terms of the Creative Commons Attribution License, which permits unrestricted use, distribution, and reproduction in any medium, provided the original author and source are credited.

\begin{abstract}
Disintegrins constitute a group of small proteins or peptides (45-85 amino acids) that function as natural antagonists of integrin receptor-dependent cell activities. The integrins themselves comprise a superfamily of hetero-dimeric (alpha and beta chains) transmembrane cell surface receptors whose functions include cell adhesion, growth, migration, and angiogenesis. In contrast, the disintegrins comprise groups of two types of molecules, namely, a) short proteins or peptides comprising insect and animal venoms; and b) intrinsic sub domain sequence fragments or short motifs present on large mammalian metalloprotease enzymes. Certain disintegrins bind specifically to tri-amino acid sequences (RGD, LGD etc) located on integrins beta- 1 and beta- 3 chains of the hetero complex receptors. Binding at such sites can inhibit or block cell migration, angiogenesis, metastasis, and platelet aggregation. Recently, small disintegrin-like peptides from naturally-occurring proteins have likewise been reported to inhibit growth and adhesion functions associated with integrin-dependent cell activities. The present report describes examples of such disintegrin-like peptides and provides support for their proposed use in adjunct cancer therapy.
\end{abstract}

Keywords: Disintegrin; Integrin; Peptide; Zinc; Metalloproteinase; Cancer; Clotting; Adhesion

\section{Introduction}

\section{General}

The containment of a class of internal growth modulatory peptide segments within a polypeptide chain of naturally-occurring proteins is a recurrent theme in cell regulation and signaling. Some of the more common growth inhibitors/suppressors consist of short amino acid sequence fragments derived from abundant plasma/serum, extracellular matrix, and angiogenesis-related proteins. Such fragment examples are: angiostatin derived from plasminogen; endostatin from collagen type XVIII; vasostatin from calreticulin, and tenecin from fibronectin [1]. While some segments are readily exposed on tertiaryfolded protein surfaces, others constitute hidden, occult, or cryptic sites revealed following unfolding, denaturization, or proteolysis of the full-length protein [2]. The present study focuses on a cryptic site peptide fragment derived from a naturally-occurring fetal protein which is presented and discussed as potential disintegrin-like peptide (DLP) proposed for adjunct cancer therapies.

\section{Types of Integrins and Disintegrins}

The integrin superfamily of cell surface receptors consists of hetero-dimeric (alpha and beta chains) transmembrane glycoproteins that mediate cell-to-extracellular matrix (ECM) and cell-to-cell adhesion interactions [1-3]. In contrast, the disintegrins (DIs) exist in two forms, namely; a) families of free small proteins/peptides of 40-85 amino acids in length present in insect and snake venoms; and b) subdomain fragments or segments of a larger metalloproteinase enzyme; moreover, both such forms are capable of blocking integrin activities, interactions, and signaling [4-9]. Below, the animal venoms and protease subdomain DIs are discussed and compared to a disintegrin-like cryptic peptide derived from a naturally-occurring protein.

\section{Objectives and Aims}

The objectives in the present report are three-fold. First, biological functions and activities of the DIs are described. Second, the types and family members of the snake venom DI molecules are discussed together with their metallproteinase subdomain counterparts. Finally, an example of a disintegrin-like fetal peptide (DLP) is described which displays activities such as inhibition of platelet aggregation, cell to matrix adhesion, cell migration, spreading, and angiogenesis. It is presently proposed that such activities of DLPs might be harnessed to provide a novel source of adjunct therapeutic cancer agents.

\section{The Disintegrins}

The free single chain (DIs) disintegrins constitute families of small proteins and peptides ranging in length from 45 to 85 amino acids (AA) in insect and snake venoms. Many DIs serve and function as toxic 
venoms that inhibit integrin-dependent activities such as: a) platelet aggregation; b) cell adhesion; c) cell signaling; and d) angiogenesis $[8,9]$. Other DIs comprise subdomain fragments inclusive on fulllength metalloproteinase enzymes [10-12]. Such free and fragment DIs function by inhibiting the clumping or aggregation of platelets [13]. This action results in unimpeded bleeding and subsequent death to the host victim. The DIs bind and interact with the beta- 1 and beta-3 chains of integrin receptors which normally serve as common pathways to aggregation via platelet-to-platelet interactions essential for thrombosis and/or hemostasis [14-16]. Certain DIs contain an RGD (Arg-GLy-Asp) or KGD (Lys-Gly-Asp) amino acid sequence motif that specifically binds to integrin IIb-IIIa receptors located on the surface membrane of platelets $[17,18]$. Other tri-amino acid single letter sequence codes include segments such as VGD, MLP, KTS, TRS, WGD, and RED [19]. The RGD-like binding event is capable of blocking the attachment of fibrinogen and von Willebrand Factor to a receptor-glycoprotein complex on platelets activated by aggregation agents such as ADP, thrombin, collagen, and platelet activating factor.

As discussed above, a wide array of true viper and pit viper venoms have been reported to consist of short peptide or protein disintegrins that block integrin-associated functions and activities [8,9]. Such or proteins peptides DIs are readily distinguished from the cobra-like venoms which are neurotoxins. Most disintegrins which contain the triamino acid or similar cell attachment recognition sequences are bordered by multiple cysteines resides $[7,8]$. Since disintegrins possess a variety of tripeptide sequences, they are further capable of inhibiting the adhesive functions of multiple integrins such as $\alpha v \beta 3$ and $\alpha v \beta 5$ (vitronectin receptors) and $\alpha 5 \beta 1$, the fibronectin receptor [13]. Thus, the disintegrins have been utilized to serve as models for designing novel and potent peptides for therapeutic use in the inhibition of platelet aggregation, blockage of the tumor-induced platelet aggregation stage of metastasis, and anti-angiogenesis during tumor development.

The second structural types of DIs consist of their presence as intrinsic subdomain sequence fragments on large metalloproteinase enzymes [20]. These proteinases comprise a family of enzymes referred to as ADAM (short for: A Disintegrin and Metalloproteinase) proteins. ADAM proteins are present either as single-pass fixed transmembrane proteins or secreted metallo-endopeptidase enzymes [21]. These peptidases exhibit multi-subdomain segments consisting of: a) a prodomain; b) a metalloprotease piece; c) a disintegrin subdomain; d) a cysteine-rich segment; e) an epidermal-growth factor-like motif; f) a transmembrane domain; and g) a C-terminal short cytoplasmic tail $[21,22]$. However, not all human ADAM proteins possess a functional protease domain suggesting a secondary role in proteinto-protein interactions for cell adhesion. ADAM proteins serving as active proteases can also cleave off and shed extracellular portions (subdomain) of their protein chain structure, such as an EGF-like fragment. The ADAM family members consist of at least 20 different types of metallo-protease enzyme members present on cells in many diverse organs and tissues.

\section{Types of disintegrin proteins/peptides}

The free single-chain disintegrins are derived largely from snake venoms such as Mojastin from Crotalusscutulatus, Salmonsin from Agkistrondon halys, and chistatin from Echis carinatus [23]. However, other DI-like peptides either free or intrinsic have been reported in mammals; these include: a guinea pig sperm (surface protein PH30), a mammalian epididymal apical protein (EAP-1), and intrinsic subdomain fragments from ADAM family proteinases such as ADAM7, ADAM-10, and ADAM-17 [24]. DIs segments can be parsed into 5 different classes depending on the number of amino acid and cysteine residues in the peptide chain $[25,26]$. The first class includes the small DIs with 40-51 AAs and 4 disulfide bonds (DS). The second (medium) class of DIs displays 60-70 AAs with 6 DS bonds. The third (large) class contains at least 80-84 AAs and 7 DS bonds. The fourth dimeric class exhibits 67 or more AAs and 4 intra-chain DS bonds. Finally, the $5^{\text {th }}$ type represent metalloproteinase subdomains containing 100 AAs and 8 DS bonds. Thus, DIs can include small to large free proteins/ peptides, dimeric components, and subdomain segments from full length metalloproteinase enzymes.

\section{Disintegrins and tumor-induced platelet aggregation}

Tumor Cell-Induced Platelet Aggregation (TCIPA), a required component of metastasis, was first described by Gasic in the early 1970s [27]. Tumor cells in the blood vasculature are frequently observed complexed and clumped with platelets; this accumulation, together with the hypercoagulable state of the malignant disease, appears to be essential for successful metastasis. The ability of tumor cells to clump with platelets and induce platelet aggregation is widespread among cancers including breast carcinoma, colon adenocarcinoma, lung carcinoma, melanomas, and others $[28,29]$. A role for platelet participation in the metastatic process is thought to result from a) direct binding of platelets to tumor cells, and b) the release of soluble inducer agents from the tumor cells. These agents include the classical platelet aggregation activators such as ADP, cathepsin B, thrombinlike proteinases, collagen, and tissue factor-generated thrombin [30]. Thus, platelets act to facilitate the intermediate steps of transvascular metastasis and migration including tumor cell retention and arrest, subendothelial interaction, and extravasation from the microvasculature. Blockage at these steps can result in retarding or reducing migration of tumor cells during metastasis. Thus, the DIs represent a class of chemical agents whose therapeutic metastatic potential has yet to be fully realized.

\section{Biological activities of Disintegrins (DIs) as anticancer agents}

The cysteine-rich DIs bind to tri-amino acid sequence loops on Integrin membrane receptors located both on normal and cancer cell surfaces. Various receptor functions which can be inhibited by the DIs include activities of tumor cells associated with cell proliferation, adhesion, invasion, migration, metastasis, cell shape alterations, locomotion via-the cytoskeleton, and cell survival $[8,9,11]$. The inhibition of tumor cell growth by DIs is well-known being reported in multiple human cancer types such as; breast, pancreas, glioblastoma, lung, melanoma, colorectal, liver, stomach, kidney, and others [14,16,31-36]. The target cells to which DIs are attracted include epithelial cells, fibroblasts, white blood cells (i.e. neutrophils), ECM cells, tumor cells, and platelets.

DI inhibition of cell proliferation has been largely attributed to GO/G1 cell cycle phase arrest rather than apoptosis and/or necrosis. Some viper DIs, such as Tablysin-15, have been reported to suppress expression of cyclin-associated proteins such as CDK2, CDK6, Cyclin-D1, and Cyclin-E [17]. Certain snake venom DIs have been found to suppress the phosphorylation of focal adhesion kinases, the Akt protein, and beta GSK. Other DIs can block NF- $\kappa B$ nuclear translocation, while increasing the expression of the CDK inhibitor p21 (CIP) which halts G2-M cell cycle progression [34-37]. Interestingly, the increased expression of p21 alone can halt cancer cell growth, proliferation, and subsequent metastasis. Finally, snake venom DIs, such as "Viper anatolica" have been labeled with radionuclide intended for integrin-targeted radiotherapy to treat brain cancer [38]. 
Similar to the viper DI-like peptides, inhibitors of the zincendopeptidase subdomain fragments belong to families' of the metalloproteases such as ADAM transmembrane enzymes $[39,40]$. These DI-subdomains associated with metalloproteases are crucial participants in regulating the cell activities of cell-to-ECM adhesion molecules, cytokines, and growth factors. Thus, the importance of the disintegrin-metalloproteinase moieties lie in their modulating the ability of cells to control their extracellular environment, from remodeling of the extracellular matrix to the interaction of cells via adhesion and signaling in receptor cross-talk networks. The mechanisms of tumor cell growth inhibition of the ADAM-family proteinase subdomain fragments resemble those of the smaller protein or peptide venoms discussed above. The ADAM-DI subdomain binds to alpha-3, $\beta 1$ integrin heterodimers, leading to cell cycle G1 phase growth arrest coupled with an enhanced expression of the cyclin-dependent kinase (CDK) inhibitor, p27 KIP1. This latter CDK inhibitor has been demonstrated to halt cell cycle progression in the G1 to $S$ phase transition [41,42].

\section{A Disintegrin-like peptide}

Other than the PH30 and EAP-1 peptide/protein described above, a further example of and is integrin-like small peptide is the growth inhibitory peptide [GIP] segment derived from full length alphafetoprotein [AFP], a tumor-associated fetal protein [41,42]. The GIP segment is a 34-mer peptide sequence that lies buried in a molecular cleft of the tertiary-folded AFP polypeptide [43,44]. Following a conformational transformation, the intrinsic 34 -amino acid presents as an exposed segment of human AFP which temporarily converts the growth-enhancing full-length AFP molecule into a growth inhibitory protein $[45,46]$. The transiently transformed growth-inhibiting AFP polypeptide present during pregnancy can temporarily halt growth until signal pathways can be repaired and restored in the fetus [47]. The transformed AFP molecule can subsequently refold into its tertiary native configuration which again conceals its growth inhibiting segment. The 34-amino acid GIP segment has been synthesized as a free peptide which has been purified and its biological activities characterized $[45,48,49]$. The free 34-mer GIP fragment has been reported to inhibit growth in breast and other human cancers in both in vivo and in vitro studies [50-52]. Interestingly, the GIP fragment demonstrates many of the activities displayed by DI peptides such as inhibition of platelet aggregation, cell/ECM adhesion and binding, and cell cycle arrest at the G1-S phase of the cell cycle (Table 1).

\section{Activities of the disintegrin-like GIP}

The AFP-derived peptide and platelet aggregation: Platelet Aggregation inhibition (PAI) has been studied using GIP in freshly prepared human platelet rich plasma preparations as previously reported $[48,49]$. The three platelet aggregation agonists used in these studies were Adenosine Diphosphate (ADP), Arachidonic Acid, (AA) and Collagen-II (Col-II) tested in platelet rich-plasma. The GIP fragment inhibited ADP induced platelet aggregation by $93 \%$, blocked ADP collagen-induced platelet aggregation by $96 \%$, and demonstrated $100 \%$ inhibition using AA. Thus, PAI occurred using all three agonists when the GIP segment was employed. Ristocetin, used a positive aggregation control, displayed $100 \%$ platelet aggregation in these studies. In summary, these data demonstrated that AFP-derived GIP was capable of PAI and that full recovery was achieved when Ristocetin was applied.

Cell adhesion assays using GIP: AFP-derived GIP was further subjected to cell adhesion studies using microtiter plates previously coated with ECM ligand proteins as attachment surfaces for two different breast cancer cell types: the human MCF-7 and the murine mammary $6 \mathrm{WI}-1$ cell lines $[48,49]$. The adhesion of MCF-7 and 6WI1 tumor cells, either in the presence or absence of GIP, was assayed on various ECM-coated microtiter plates. GIP was capable of inhibiting cell adhesion of the ECM ligand proteins in both tumor cell lines by $30-60 \%$. Inhibition of mouse and human tumor cell adhesion was roughly equivalent in microtiter plates coated with either collagen IV, fibrinogen, fibronectin, thrombospondin, laminin, collagen-I, or vitronectin. As a result, human MCF-7 breast cancer cells in the presence of GIP, displayed $60 \%$ inhibition to vitronectin-induced adhesion, while mouse 6WI-1 cells demonstrated $40-50 \%$ peptide inhibition of tumor-to-laminin adhesion. Overall, the AFP peptide was found to competitively inhibit both MCF-7 and 6WI-1 cellto-ligand attachment ranging from $40-60 \%$ in the various ligands employed $[48,49]$.

Inhibition of cell migration, spreading, and metastases by GIP: Cell adhesion receptors and their ligands, (i.e., ECM proteins), provide the traction and stimulus for the migration and spreading of tumor cells both in vivo and in vitro $[48,49]$. Integrins mediate migration of adherent cells such as fibroblasts, epithelial cells, and tumor cells on ECM tissues and/or surfaces. Cell migration requires multivalent binding of integrins to matrix bound ligands such as collagen, laminin, and fibronectin [4,5]. Analysis of cell migration assays using GIP revealed that the peptide GIP was capable of inhibiting more than $60 \%$ of the MCF-7 cancer cells' spreading and migration on the surfaces of covers to be in vitro. The cells that inhibited migration displayed distorted morphology such as star-shaped configurations, cytoplasmic spiking, surface spiny spheres, membrane ruffling, and extensions of cytoplasmic processes; these events were coupled with low cell viability. It is important to note that cell migration and spreading constitute crucial steps in the cancer metastatic process; in this regard, GIP has been further reported to inhibit metastases in various animal models $[44,49]$.

The AFP-derived peptides as anti-angiogenic agents: Angiogenesis, the formation of new capillaries from pre-existing blood vessels, is required for growth of solid tumors as well as in pregnancy, wound healing, tissue repair, placentation, and embryonic development [53]. The angiogenic process is composed of complex, multi-step stages encompassing four major events: 1) Cell migration, 2) proliferation of cells (endothelial), 3) cell survival, and 4) vessel tube assembly formation [54]. Thus, angiogenesis involves multiple cells, structures, and activities including ECM adherent cell activities, basement membrane alterations, cytoskeletal-induced cell shape changes, cell aggregation, receptor clustering, and ECM-to-integrin interaction [55]. Antagonism of the above constituents and associated events determine an agent to be an anti-angiogenic factor such as a disintegrin. Inhibition of these angiogenic events prevents the final assembly of endothelial cells into capillary tubes structures, i.e., tubulogenesis, which constitutes the endpoint of the angiogenic process. Moreover, without the first three stages of the angiogenic process (cell migration, proliferation, and cell survival), capillary vessel tube assembly cannot ensue.

\section{The Chick Allantoic Membrane Assay of Egg Shell Membrane Vascularization}

The Chick Allantoic Membrane (CAM) assay is a measure of blood vessel capillary structure formation on the inner membrane of the chicken eggshell [56]. Thus, the CAM assay serves as a rapid screening method of evaluating angiogenic agents in living systems. GIP was assayed for its anti-angiogenic properties in a tumor-angiogenesis 
Table 1: A Comparative Listing of Activities and Traits Demonstrated by Free Disintegrins-Peptides and Protein Subdomain Components versus the Growth Inhibitory Peptide (GIP)*.

\begin{tabular}{|c|c|c|c|}
\hline Activities, actions, traits, properties & Soluble and fixed Disintegrins & $\begin{array}{l}\text { Disintegrin-like Peptides Example: Growth } \\
\text { Inhibitory Peptides }\end{array}$ & \\
\hline Platelet aggregation & Inhibits Platelet aggregation & Inhibits Platelet aggregation & 48,49 \\
\hline Integrin Cell Adhesion & Inhibits/blocks cell adhesion & Inhibits/blocks cell adhesion & 18,19 \\
\hline Angiogenesis & Inhibits angiogenesis & Inhibits angiogenesis & $57-60$ \\
\hline RGD binding recognition sequence & $\begin{array}{l}\text { Contains, RGD, KGD tripeptide binding } \\
\text { sequences }\end{array}$ & Recognizes RHE tripeptide binding sequence & 22,45 \\
\hline Binds Integrin chains Beta- 1 and Beta- 3 & Binds Beta- 1 and Beta- 3 chains & Binds Beta- 1 and Beta- 3 chains & $4-6$ \\
\hline Fixed and Soluble ECM Ligand Binding & Inhibits fixed and soluble Ligand binding & Inhibits fixed and soluble Ligand binding & 5,6 \\
\hline Cell migration invasion and spreading & Blocks cell migration and spreading & Blocks cell migration and spreading & 22,24 \\
\hline Cell/organism localization & $\begin{array}{l}\text { Insect/snake venoms and ADAMS Family } \\
\text { protein }\end{array}$ & $\begin{array}{l}\text { Subdomain of oncofetal protein (alpha- } \\
\text { fetoprotein) }\end{array}$ & $7-9$ \\
\hline $\begin{array}{l}\text { Hemostatic status/cytoskeletal } \\
\text { classification }\end{array}$ & $\begin{array}{l}\text { Hemorrhagic, attaches to cytoskeletal } \\
\text { proteins }\end{array}$ & $\begin{array}{l}\text { Non-hemorrhagic, attaches to cytoskeletal } \\
\text { proteins }\end{array}$ & 11,12 \\
\hline $\begin{array}{l}\text { Down Regulates expression of ADAM } \\
\text { proteins }\end{array}$ & $\begin{array}{l}\text { Changes of expression on ADAM 9, 10, } \\
12 \text {, and } 17\end{array}$ & Down regulates expression of ADAM-22 & $58,54,60$ \\
\hline Cell toxicity & $\begin{array}{l}\text { Forms fusion toxins, induces } \\
\text { hemorrhaging, binds integrin receptor }\end{array}$ & $\begin{array}{l}\text { No known side ill effects; binds integrin } \\
\text { receptor }\end{array}$ & $33-35$ \\
\hline Working concentration ranges & Nanogram to microgram concentrations & Nanogram to microgram concentrations & 5,6 \\
\hline Cell targets & $\begin{array}{l}\text { Integrin bearing metastatic cells, platelets } \\
\text { ECM cells, neutrophil }\end{array}$ & $\begin{array}{l}\text { Platelets, metastatic cells, cancer cells, ECM } \\
\text { cells }\end{array}$ & $9,10,60$ \\
\hline Cell penetration and internalization & No known activity; no capability & $\begin{array}{l}\text { Fusogenic cell penetrating peptide } \\
\text { (microbial-like) }\end{array}$ & 59,60 \\
\hline Anticancer activities and properties & $\begin{array}{l}\text { Cytotoxic, cell detachment effect on } \\
\text { Breast/other cancers }\end{array}$ & $\begin{array}{l}\text { Cytostatic effect, inhibits cancer growth on } \\
\text { (breast) multiple cancers }\end{array}$ & $1-3,51,52$ \\
\hline Platelet-to-cancer cell adhesion & Blocks platelet-to-cancer cell adhesion & Inhibits platelet-to-cancer cell adhesion & 56,57 \\
\hline Effect on cell cycle progression & Induces $\mathrm{G0}$ to $\mathrm{G} 1$ phase cell cycle arrest & Induces $\mathrm{G} 1$ to $\mathrm{S}$ phase cell cycle arrest & $28,37,51$ \\
\hline Unique peptide characteristic & Cysteine-rich and beta-hairpin loops & Cysteine-rich and beta-hairpin loop & $38-40,51$ \\
\hline $\begin{array}{l}\text { Number of amino acids on peptide or } \\
\text { protein subdomain }\end{array}$ & $\begin{array}{l}40 \text { to } 85 \text { amino acid in length. (Viper } \\
\text { snake Venoms) }\end{array}$ & Peptide of 34-36 amino acids in length & $39,40,59$ \\
\hline Tumor cell metastasis & Inhibits tumor cell metastasis & Inhibits tumor cell metastasis & 50,51 \\
\hline
\end{tabular}

Legend:*GIP derived from alpha-fetoprotein; ADAM=A Disintegrin and Metalloproteinase; RGD=Arg-Gly-Asp; KGD=Lys-Gly-Asp; RHE=Arg-His-Glu

model using the CAM assay in incubating chicken eggs [57]. In the CAM assay, mouse C5B1 melanomas were implanted on the egg shell inner membranes on incubation day 6 and observed $72 \mathrm{hr}$ later for angiogenic vascular patterns which surround and attach to the tumor mass [49]. The results of these data demonstrated that GIP was capable of inhibiting of 95-100\% tumor vascular growth induced by fibroblast growth factor (FGF) in the tumors which were transplanted onto the eggshell inner membrane.

\section{Further Activities of Disintegrin-like Peptides}

Recombinant and chimeric forms of DTs and ADAM subdomain fragments have been synthesized for use in studies of integrin inhibition of tumor growth, proliferation, adhesion, migration and angiogenesis of cancers such as liver, breast, lungs, and melanomas, $[15,53,58,59]$. In addition, the DI-like GIP has been reported to induce apoptosis in both radio-and chemo-sensitized cultured lymphocytes
[49]. It has been further reported that ADAM-22 subdomain is an active participant in the development of breast cancer resistance during endocrine hormone therapy in women $[59,60]$. In lieu of this latter report, GIP administered to cultured MCF-7 human breast cancer cells for 7 days was shown to down-regulate the expression of ADAM-22 by 30 -fold as determined by global RNA microarray analysis [51]. These data demonstrated that GIP treatment in MCF7 cultured cells clearly down-regulated the expression of ADAM-22; in effect, this event might be capable of blocking the development of hormone-resistance in breast cancer cells.

\section{Concluding Remarks}

It appears plausible that interference with integrin signaling by DIs or DILs could provide a rational basis for the development of adjunct treatment modalities for cancer growth, progression, metastases, and angiogenesis. Anti-integrin antibodies, disintegrins- and DI- 
like peptides have already shown promise in preclinical anti-cancer therapy studies. Integrin interruption of the adhesive interaction of tumor-to-tumor cells/platelets has been shown to arrest cancer growth progression and metastasis [14]. Disintegrin-like agents that block or interfere with the initial attachment of integrins to ECM components, might possibly blunt signal transduction events potentially inhibiting proliferation, cell migration/invasion, angiogenesis, and platelet aggregation. Such agents might serve to constitute a formidable armamentarium of non-toxic anti-cancer agents.

Since integrin dysfunction frequently results in cancer pathology, integrins represent an appealing set of targets for anti-tumor therapy. Because DIs specifically binds integrins, they could serve to interfere with and block integrin functions in cancer cell growth and proliferation as shown above. All such activities suggest that integrins could be viable candidates as molecular cancer targets and as such, make DIs and DLPs potential adjunct therapeutic agents to inhibit cancer growth and proliferation.

\section{Conflict of Interest}

The author declares that there are no known conflicts of interest in the preparation of this manuscript.

\section{Financial Disclosures}

None; no U.S. federal grants were used in the preparation of this paper.

\section{References}

1. Yoshikawa J (2015) Bioactive peptides derived from natural proteins with respect to diversity of their receptors and physiological effects. Peptides 72: 208-225.

2. Vajda S, Beglov D, Wakefield AE, Egbert M, Whitty A (2018) Cryptic binding sites on proteins: definition, detection and druggability. Curr Opin Chem Biol 44: 1-8.

3. Muehlemann M, Miller KD, Dauphinee M, Mizejewski GJ (2005) Review of Growth Inhibitory Peptide as a biotherapeutic agent for tumor growth, adhesion, and metastasis. Cancer Metastasis Rev 24: 441-467.

4. Hamidi H, Ivaska J (2018) Every step of the way: integrins in cancer progression and metastasis. Nat Rev Cancer 18: 533-548.

5. Desgrosellier JS, Cheresh DA (2010) Integrins in cancer: biological implications and therapeutic opportunities. Nat Rev Cancer 10: 9-22.

6. Sequin L, Desgrosellier JS, Weis SM, Cheresh DA (2015) Integrins and cancer: regulators of cancer stemness, metastasis, and drug resistance. Trends Cell Biol 25: 234-240.

7. Swenson SD, Silva-Hirschberg C, Markland FS (2020) Methods for evaluation of a snake venom-derived disintegrin in animal models of human cancer. Methods Mol Biol 2068: 185-204.

8. Arruda Macêdo JK, Fox JW, de Souza Castro M (2015) Disintegrins from snake venoms and their applications in cancer research and therapy. Curr Protein Pept Sci 16: 532-548.

9. Calderon LA, Sobrinho JC, Zaqueo KD, de Moura AA, Grabner AN, et al. (2014) Antitumoral activity of snake venom proteins: new trends in cancer therapy. Biomed Res Int 20: 203639.

10. Gillian M (2011) Tissue inhibitors of metalloproteinases. Genome Biol 12: 233.

11. Baker AH, Edwards DR, Murphy G (2002) Metalloproteinase inhibitors: biological actions and therapeutic opportunities. J Cell Sci 115: 3719-3727.
12. Saha N, Robev D, Himanen JP, Nikolov DB (2019) ADAM proteases: Emerging role and targeting of the non-catalytic domains. Cancer Lett 467: 50-57.

13. Mizejewski GJ (1999) Role of integrins in cancer: survey of expression patterns. Proc Soc Exp Biol Med 222: 124-138.

14. Dhananjaya BL, Sivashankari PR (2015) Snake venom derived molecules in tumor angiogenesis and its application in cancer therapy; an overview. Curr Top Med Chem. 15: 649-657.

15. Higuchi DA, Almeida MC, Barros CC, Sanchez EF, Pesquero PR, et al. (2011) Leucurogin, a new recombinant disintegrin cloned from Bothrops leucurus (white-tailed-jararaca) with potent activity upon platelet aggregation and tumor growth. Toxicon 58: 123-129.

16. Zuo XX, Yang $Y$, Zhang $Y$, Zhang ZG, Wang XF, et al. (2019) Platelets promote breast cancer cell MCF-7 metastasis by direct interaction: surface integrin $\alpha 2 \beta 1$-contacting-medicated activation of Wnt- $\beta$ catenin pathway. Cell Commun Signal 17: 142.

17. Deng Z, Chai J, Zeng Q, Zhang B, Ye T, et al. (2019) The anticancer properties and mechanisms of action of tablysin-15, the RGDcontaining disintegrin, in breast cancer cells. Int J Biol Macromol 129: $1155-1167$.

18. Cominetti MR, Martin AC, Ribeiro JU, Djaafri I, Fauvel-Lafeve F, et al. (2009) Inhibition of platelets and tumor cell adhesion by the disintegrin domain of human ADAM9 to collagen under dynamic flow conditions. Biochimie 91: 1045-1052.

19. Assumpcao TC, Ribeiro JM, Francischetti IM (2012) Disintegrins from Hematophagous Sources. Toxins 4: 296-322.

20. Lu X, Lu D, Scully MF, Kakkar VV (2005) Snake venom metalloproteinase containing a disintegrin-like domain, its structureactivity relationships at interacting with integrins. Curr Med Chem Cardiovasc Hematol Agents 3: 249-260.

21. Edwards DR, Handsley MM, Pennington CJ (2008) The ADAM metalloproteinases. Mol Aspects Med 29: 258-289.

22. Pather K, Dix-Peek T, Duarte R, Chetty N, Augustine TN (2019) Breast cancer cell-induced platelet activation is compounded by tamoxifen and anastrozole in vitro. Thromb Res 177: 51-58.

23. Waheed H, Moin SF, Choudhary MI (2017) Snake venom: from deadly toxins to life-saving therapeutics. Curr Med Chem 24: 18741891.

24. Kelwick R, Desanlis I, Wheeler GN, Edwards DR (2015) The ADAMTS (A Disintegrin and Metalloproteinase with Thrombospondin motifs) family. Genome Biol 16: 113.

25. Bilgrami S, Yadav S, Kaur P, Sharma S, Perbandt M, et al. (2005) Crystal structure of the disintegrin heterodimer from saw-scaled viper (Echis carinatus) at 1.9 A resolution. Biochemistry 44: 1105811066.

26. Monleon D, Esteve V, Kovacs H, Calveta JJ, Celda B (2005) Conformation and concerted dynamics of the integrin-binding site and the C-terminal region of echistatin revealed by homonuclear NMR. Biochem J 387: 57-66.

27. Gasic GJ, Boettiger D, Catalfamo JL, Gasic TB, Stewart GJ (1978) Aggregation of platelets and cell membrane vesiculation by rat cells transformed in vitro by Rous sarcoma virus. Cancer Res 38: 29502955.

28. Sun L, Li Q, Guo Y, Yang Q, Yin J, et al. (2020) Extract of Caulis Spatholobi, a novel platelet inhibitor,efficiently suppresses metastasis of colorectal cancer by targeting tumor cell-induced platelet aggregation. Biomed Pharmacother 123: 109718. 
29. Casalou C, Faustino A, Silva F, Ferreira IC, Vaqqueirinho D, et al. (2019) Arl13b regulates breast cancer cell migration and invasion by controlling integrin-mediated signaling. Cancers (Basel) 11: 1461.

30. Karczewski J, Connolly TM (1997) The interaction of disagregin with the platelet fibrinogen receptor, glycoprotein IIb-IIla. Biochem Biophy Res Commun 241: 744-748.

31. Lewczuk L, Pryczynicz A, Guzinska-Ustymowicz K (2019) Cell adhesion molecules in endometrial cancer-a systematic review. Adv Med Sci 64: 423-429.

32. Lin E, Wang Q, Swenson S, Jadvar H, Groshen S, et al. (2010) The disintegrin controstatin combination with docetaxel is a potent inhibitor of prostate cancer in vitro and in vivo. Prostate 70: 13591370.

33. Uzair B, Atlas N, Malik SB, Jamil N, Ojuolape ST, et al. (2018) Snake venom as an effective tool against colorectal cancer. Protein Pept Lett 25: 626-632.

34. Mino N, Miyahara R, Nakayama E, Takahashi T, Takanhashi A, et al. (2009) A disintegrin and metalloprotease 12 (ADAM12) is a prognostic factor in resected pathological stage 1 lung adenocarcinoma. J Surg Oncol 100: 267-272.

35. Kim JM, Jeung HC, Rha SY, Yu EJ, Kim TS, et al. (2014) The effect of disintegrin-metalloproteinase ADAM9 in gastric cancer progression. Mol Cancer Ther 12: 3074-3085.

36. Miltyk W, Surazyński A, Slawomir W, Palka JA (2009) Combined therapy with disintegrin and melphalan as a new strategy in inhibition of endometrial cancer cell line (Ishikawa) growth. Folia Histochem Cytobiol 47: S121-S125.

37. Moreno-Layseca P, Streuli CH (2014) Signaling pathways linking integrins with cell cycle progression. Matrix Biol 34: 144-153.

38. Er O, Eksin E, Soylu H, Gocmen B, Nalbantsoy A, et al. (2019) Investigation of Vipera Anatolica Venom Disintegrin via Intracellular Uptake with Radiolabeling Study and Cell-Based Electrochemical Biosensing Assay. Appl Biochem Biotechnol 187: 1539-1550.

39. Dreymueller D, Theodorou K, Donners M, Ludwig A (2017) Fine tuning cell migration by a disintegrin and metalloproteinases. Mediators Inflamm 2017: 9621724

40. Choi GC, Li J, Wang Y, Li L, Zhong L, et al. (2014) The metalloprotease ADAMTS8 displays antitumor properties antagonizing EGFR-MEDERK signaling and is silenced in carcinomas by $\mathrm{CpG}$ methylation. Mol cancer Res 12: 228-238.

41. Mizejewski GJ (2001) Alpha-fetoprotein structure and function: relevance to isoforms, epitopes, and conformational variants. Exp Biol Med (Maywood) 226: 377-408.

42. Mizejewski GJ (1997) Alpha-fetoprotein as a biologic response modifier: relevance to domain and subdomain structure. Proc Soc Exp Biol Med 215: 333-362.

43. Mizejewski GJ, MacColl R (2003) Alpha-fetoprotein growth inhibitory peptides: potential leads for cancer therapeutics. Mol Cancer Ther 2: $1243-1255$

44. Mizejewski GJ, Muehlemann M, Dauphinee M (2006) Update of alpha fetoprotein growth-inhibitory peptides as biotherapeutic agents for tumor growth and metastasis. Chemotherapy 52: 83-90.

45. Mizejewski GJ, Dias JA, Hauer CR, Henrikson KP, Gierthy J (1996) Alpha-fetoprotein derived synthetic peptides: assay of an estrogenmodifying regulatory segment. Mol Cell Endocrinol 118: 15-23.
46. Mizejewski GJ, Eisele L, MacColl R (2006) Anticancer versus antigrowth activities of three analogs of the growth-inhibitory peptide: relevance to physicochemical properties. Anticancer Res 26: 3071-3076.

47. Bartha JL, Illanes S, Gonzalez-Bugatto F, Abdel-Fattah SA, Mizejewski GJ, et al. (2007) Maternal serum transformed alpha-fetoprotein levels in women with intrauterine growth retardation. Fetal Diagn Ther 22: 294-298.

48. Muehlemann M, Miller KD, Dauphinee M, Mizejewski GJ (2005 Review of growth inhibitory peptide as a biotherapeutic agent for tumor growth, adhesion, and metastasis. Cancer Metastasis Rev 3 : 441-467.

49. Mizejewski GJ, Butterstein G (2006) Survey of functional activities of alpha-fetoprotein derived growth inhibitory peptides: review and prospects. Curr Protein Pept Sci 7: 73-100.

50. Mizejewski GJ, Mirowski M, Garnuszek P, Maurin M, Cohen BD, et al. (2010) Targeted delivery of anti-cancer growth inhibitory peptides derived from human alpha-fetoprotein: review of an international multi-center collaborative study. J Drug Target 8: 575-588.

51. Mizejewski GJ (2011) Mechanism of cancer growth suppression of alpha-fetoprotein derived growth inhibitory peptides (GIP): comparison of GIP-34 versus GIP-8 (AFPep). Updates and prospects. Cancers (Basel) 3: 2709-2733.

52. Mizejewski G, Smith G, Butterstein G (2004) Review and proposed action of alpha-fetoprotein growth inhibitory peptides as estrogen and cytoskeleton-associated factors. Cell Biol Int 28: 913-933.

53. Lucena SE, Romo K, Suntravat M, Sanchez EE (2014) Anti-angiogenic activities of two recombinant disintegrins derived from the Mohave and Prairie rattlesnakes. Toxicon 78: 10-17.

54. Flamme L, Frolich T, Risaw W (1997) Molecular mechanism of vasculogenesis and embryonic angiogenesis. J Cell Physiol 173: 206210.

55. Avraanides CJ, Garny-Susmi, Varner JA (2008) Integrins in angiogenesis and lymphangiogenesis. Nature Rev Cancer 8: 604617.

56. Nguyen M, Shing Y, Folkman J (1994) Quantitation of angiogenesis and antiangiogenesis in the chick embryo chorioallantoic membrane. Microvasc Res 47: 31-40.

57. Knighton D, Ausprunk D, Tapper D, Folkman J (1977) Avascular and vascular phases of tumour growth in the chick embryo. Br J Cancer 35: 347-356.

58. Hou Y, Chu M, Du FF, Lei JY, Chen Y, et al. (2013) Recombinant disintegrin domain of ADAM15 inhibits the proliferation and migration of Bel-7402 cells. Biochem Biophys Res Commun 435: 640-650.

59. David V, Succar BB, deMoraes JA, Saldanha-Gama RFG, Barja-Fidalgo C, et al. (2018) Recombinant and chimeric disintegrins in preclinical research. Toxins (Basel) 10: 321.

60. McCartan D, Bolger JC, Fagan A, Byrne C, Hao Y, et al. (2012) Global characterization of the SRC-1 transcriptome identifies ADAM22 as an ER-independent mediator of endocrine-resistant breast cancer. Cancer Res 72: 220-229. 